\title{
The Effect of Submerged-Vanes on Formation Location of the Saddle Point in Lateral Intake from a Straight Channel
}

\author{
Seyed Hessam Seyed Mirzaei ${ }^{1}$, Seyed Ali Ayyoubzadeh ${ }^{1, *}$, Ali Reza Firoozfar ${ }^{2}$ \\ ${ }^{1}$ Department of Water Structures Engineering, Faculty of Agriculture, Tarbiat Modares University, Tehran, Iran \\ ${ }^{2}$ IIHR-Hydroscience \& Engineering, the University of Iowa, Iowa City, IA, USA \\ *Corresponding author: ayyoub@modares.ac.ir
}

Received March 24, 2013; Revised June 10, 2013; Accepted February 19, 2014

\begin{abstract}
One of the most important problems that the river engineers have long been faced with lateral intake from rivers is sedimentation in intakes. Formation of the saddle point nearby the intake entrance is one of the main reasons for entry of the sediments into the intake channel. Using the structures in the rivers causes change of the flow pattern and consequently changing of the formation location of the saddle point. The submerged vanes are one of the structures that are installed with different dimensions and configuration in front of the intake channel to control the sediment issues,. In this study the impact of the submerged vanes dimensions and configuration on the formation location of saddle point has been investigated. The FLUENT mathematical model has been used for the simulation. Various range of the parameters has been considered for them based on the recommended range, and the simulations have been performed in three intake ratios of $0.11,0.16$ and 0.21 . The results showed that increasing the vanes height has a positive effect on intake conditions, and results in formation of the saddle point in a distance farther from the intake entrance and omission of the return flows. Utilization of submerged vanes with larger transverse distance is better for intake from rivers as no flow from downstream side of the intake channel returns to it. As the intake ratio increases the saddle point forms at a distance closer to the intake entrance, and the return flows are entered into the intake from the downstream corner of the intake entrance. Formation location of the saddle point is independent from other parameters.
\end{abstract}

Keywords: submerged vanes, saddle point, lateral intake, straight channel, fluent mathematical model

Cite This Article: Seyed Hessam Seyed Mirzaei, Seyed Ali Ayyoubzadeh, and Ali Reza Firoozfar, "The Effect of Submerged-Vanes on Formation Location of the Saddle Point in Lateral Intake from a Straight Channel." American Journal of Civil Engineering and Architecture, vol. 2, no. 1 (2014): 26-33. doi: 10.12691/ajcea-2-1-3.

\section{Introduction}

One of the important issues in intake from rivers is, controlling the sediment entering into the intake channel. From the important factors effective in transportation of the sediments accumulated in front of the intake entrance into the intake channel is the formation of a point on downstream side of the intake channel known as saddle point (Figure 1). By the collision of flow to the downstream corner of the intake entrance, the water particles are inclined downward. Combination of this flow and the secondary flows causes formation of the saddle point. In formation process of the saddle point, the secondary flow interaction in the intake entrance, the above mentioned continual downward flow and the secondary flow inside the main channel play the major role. The presence of secondary flow in front of the intake entrance causes part of the near bed particles accumulated at downstream corner of the intake entrance, to deviate towards inside of the intake and facilitate formation of flows that are called return flows (Figure 1).

No comprehensive studies have been undertaken so far concerning the saddle point, and most of the performed researches have been part of the pervious studies that have dealt with giving brief explanation in this regard.

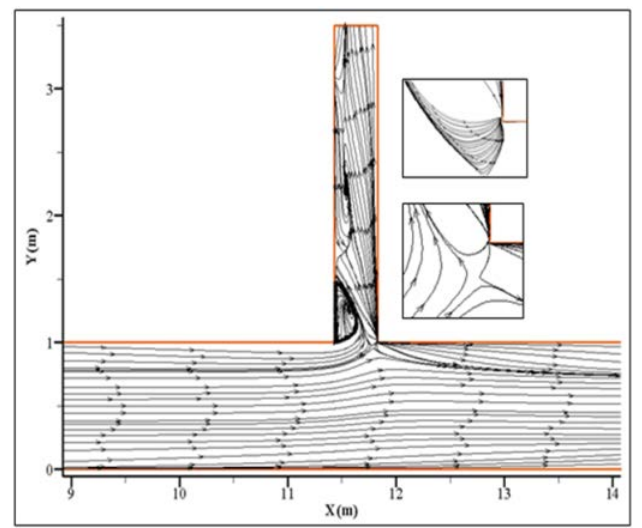

Figure 1. Formation location of the saddle point and return flows 
Barkdoll (1997) has mentioned formation of the saddle point near downstream side of the intake channel, and formation of the return flows [1].

Neary et all (1999) developed a numerical model for predicting the turbulent flow at a flat-bed diversion channel, and the saddle point was investigated. The result showed that the saddle point forms just downstream of the junction within the branch channel, acts as an entrance point for near bed flows and bed load into the intake channel [3].

Review of the previous studies show that no research has been undertaken so far to investigate the submerged vanes dimensions and configuration effects on formation location of saddle point. Studying saddle point formation provides a better insight into the phenomenon and can result in reduction of sedimentation rate in lateral intakes.

\section{Materials and Methods}

In this section, first the mathematical model and governing equations are described, and then the computational domain, boundary conditions, grid layout and software validation are presented, respectively.

\subsection{Model Description}

In this research the simulations are done using FLUENT mathematical model, a CFD solver for modeling heat transfer, fluid flow, and chemical reaction. In this model, control volume method is used to solve the threedimensional equations in general curvilinear coordinates, for both turbulent and laminar flows. To construct discrete algebraic equations for dependent variables the governing equations are integrated over each control volume. An implicit method is used for linearization of these discrete equations. In FLUENT turbulent flows can be simulated using the standard K- $\varepsilon$, LES, RNG, or the Reynolds-stress (RSM) closure schemes. For optimizing computational efficiency, the user can choose between various spatial (Second-order upwind, first-order, QUICK) discretization scheme. In this research, SIMPLE algorithm is used for Pressure-Velocity Coupling Method and second order upwind discretization scheme for Pressure, Momentum, Turbulent kinetic energy and turbulent dissipation rate. Also, the RSM turbulence model is used in the present study.

\subsection{Governing Equations}

The governing equations for unsteady free surface incompressible turbulent flow that are known as RANS ${ }^{1}$ are as follows [2]:

$$
\begin{gathered}
\frac{\partial u_{i}}{\partial x_{i}}=0 \\
\frac{\partial u_{i}}{\partial t}+u_{j} \frac{\partial u_{i} u_{j}}{\partial x_{j}}=-\frac{1}{\rho} \frac{\partial P}{\partial x_{i}}+g_{x i}+\frac{\partial}{\partial x_{i}}\left(\tau_{i j}\right)
\end{gathered}
$$

Where $t$ is time; $u_{i}$ is the velocity in the $x_{i}$ direction; $P$ is the pressure; $g_{x i}$ is the gravitational acceleration in the $x_{i}$ direction, $\rho$ is the density of fluid and $\tau$ is the stress tensor that for turbulent flow is defined as follows [2]:

\footnotetext{
${ }^{1}$ Reynolds-Averaged Navier-Stokes
}

$$
\tau_{i j}=\left[\rho\left(v+v_{t}\right)\left(\frac{\partial U_{i}}{\partial x_{j}}+\frac{\partial U_{j}}{\partial x_{i}}\right)\right]-\left[\frac{2}{3} \rho\left(k+v_{t}\right) \frac{\partial U_{j}}{\partial x_{i}} \partial_{i j}\right](3)
$$

The under-relaxation factors are chosen between 0.2 and 0.5 . For the stability of the solution of interpolation scheme the small value of the under-relaxation factors are required. Any of the several existing turbulence models can be used for closing turbulent stresses in Reynoldsaveraged equations. Each model has certain advantages over the others depending on the type and the nature of the flow field to be simulated and the desired accuracy of results, and no single turbulence model is accepted universally for solving all closes of problems [2]. Closure of the RANS equations in the Reynolds stress model (RSM) is provided by solving transport equations for Reynolds stresses and an equation for energy dissipation rate (four-equation for $2 \mathrm{D}$ flows and seven-equation for 3D flows). This turbulence model has greater potential to give accurate predictions for complex flows since it accounts for the effects of streamline curvature, swirl, rotation, and rapid changes in strain rate in a more rigorous manner than one-equation and two-equation models [5].

\subsection{Computational Domain Properties}

As can be seen from Figure 2, the computational domain is a flume of $18 \mathrm{~m}$ length, that an 90 intake channel crosses it at $11.43 \mathrm{~m}$ from its beginning. The widths of the main and intake channels are $1 \mathrm{~m}$ and $0.4 \mathrm{~m}$ respectively and all walls are rigid. Two rows of submerged vanes have been considered in front of the intake port, and in each row there are 5 submerged vanes. The variation range of the dimensions and configuration of the vanes have been considered based on the recommended range [5]. Table 1 shows the variation range of the considered parameters, where $\delta_{\mathrm{s}}=$ vanes longitudinal distance, $\delta_{\mathrm{n}}=$ vanes transverse distance, $\delta_{\mathrm{b}}=$ distance of the first row of the vanes from the intake, $\alpha=$ angle of the vanes with respect to the flow direction, $\mathrm{H}_{\mathrm{v}}$ and $\mathrm{L}_{\mathrm{v}}$ are the vanes height and length respectively, and $\mathrm{d}$ is the flow depth. Also in Table 2 the hydraulic properties of the domain are given.

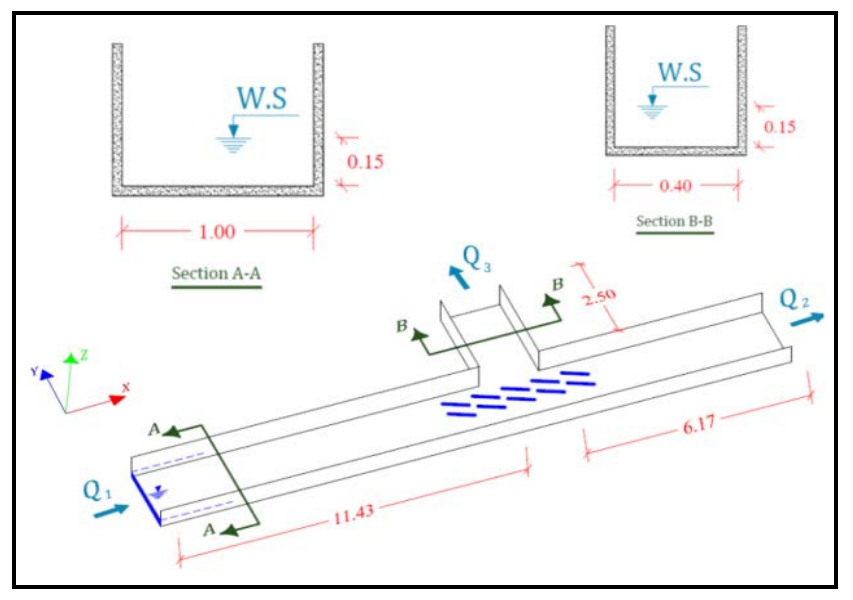

Figure 2. Geometry of the model (all dimensions in meter)

Table 1. The variation range of the considered parameters

\begin{tabular}{|c|c|c|c|c|c|}
\hline$\delta_{\mathrm{n}}$ & $\alpha$ & $\delta_{\mathrm{n}}$ & $\delta_{\mathrm{s}}$ & $\mathrm{L}_{\mathrm{v}}$ & $\mathrm{H}_{\mathrm{v}}$ \\
\hline $3 \mathrm{H}_{\mathrm{v}}$ & $25^{\circ}-15^{\circ}$ & $3) \mathrm{H}_{\mathrm{v}}-(2$ & $10) \mathrm{H}_{\mathrm{v}}-(8$ & $(3-4) \mathrm{H}_{\mathrm{v}}$ & $(0.2-0.5) \mathrm{d}$ \\
\hline
\end{tabular}


Table 2. Hydraulic parameters of the computational domain

\begin{tabular}{|c|c|c|c|c|}
\hline $\begin{array}{c}\text { Inlet }\left(\mathrm{Q}_{1}\right) \\
(\mathrm{Lit} / \mathrm{s})\end{array}$ & $\begin{array}{c}\text { Intake Ratio }\left(\mathrm{Q}_{\mathrm{r}}\right) \\
\left(\mathrm{Q}_{1} / \mathrm{Q}_{2}\right)\end{array}$ & $\begin{array}{c}\text { Flow Depth(d) } \\
(\mathrm{m})\end{array}$ & Fr & Re \\
\hline \multirow{3}{*}{58} & 0.11 & \multirow{3}{*}{0.15} & \multirow{2}{*}{0.32} & \multirow{2}{*}{57607} \\
\cline { 2 - 2 } & 0.16 & & & \\
\cline { 2 - 3 } & 0.21 & & & \\
\hline
\end{tabular}

In this study, four simulations with $0.1 \mathrm{H}_{\mathrm{v}}$ for vanes height, two simulations with $1 \mathrm{H}_{\mathrm{v}}$ for vanes length, three simulations with $1 \mathrm{H}_{\mathrm{v}}$ for the longitudinal distances between the vanes, two simulations with $1 \mathrm{H}_{\mathrm{v}}$ for the transverse distances, and for the angle between the vanes and the flow direction, three simulations with $5^{\circ}$ distances have been made. For investigating the effect of intake ratio three discharge ratios of $0.11,0.16$ and 0.21 have been considered.

\subsection{Boundary Conditions}

Velocity-inlet boundary condition was defined at inlet section. For both intake and main channel outlets the outflow boundary condition was chosen. Symmetry boundary condition was utilized for water surface because the Froude number was less than 0.4 , and water surface could be replaced by a flat rigid lid [6]. The walls, bottom surfaces and submerged vanes were defined as wall boundary condition. In Figure 3 the specified boundary conditions are shown.

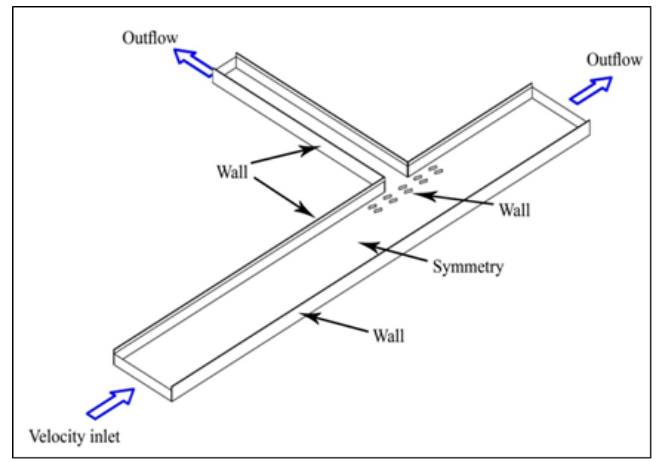

Figure 3. Boundary conditions of the model

\subsection{Grid Layout}

Wall function is used in RSM turbulence model to link the solution variables at the near-wall cells and the corresponding quantities on the wall. Therefore it is necessary to choose a suitable grid near to the walls. Since in this model there is no need to use fine meshes in the regions below the transitional region, therefore, the distance of the first node perpendicular to the wall $\left(\mathrm{y}_{1}\right)$ is determined using [2]:

$$
\begin{gathered}
\frac{\bar{c} f}{2} \approx 0.0359 \mathrm{Re}^{-0.2}=0.004 \\
u_{\tau}=\sqrt{\frac{\tau_{w}}{\rho}}=U_{e} \sqrt{\frac{\bar{c} f}{2}}=0.024 \frac{\mathrm{m}}{\mathrm{s}} \\
y_{1}=\frac{50 v}{u_{\tau}}=0.002 \mathrm{~m}
\end{gathered}
$$

Where the $\frac{\bar{c}_{f}}{2}$ is the shell friction coefficient, $u_{\tau}$ is the shear velocity, and $y_{1}$ is the first node's distance from the wall. A sample of the computational grid is shown in Figure 4.

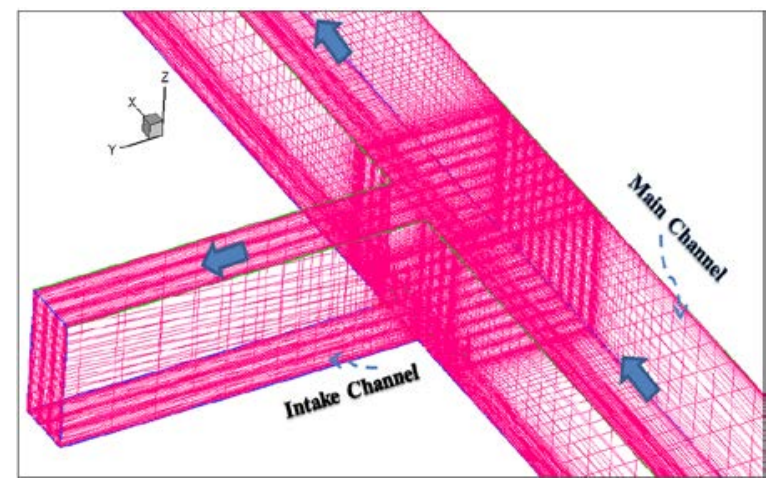

Figure 4. A sample of the computational grid

\subsection{Software Validation}

To validate the numerical model, a simulation was done for which all flume and vanes properties were similar to Omidbeigy's experimental research (2010) that was done in the hydraulic laboratory at the department of water structures Engineering, Tarbiat Modares University, Tehran, Iran.

In Figure 5 the numerical and experimental transverse profiles of velocity at $Z=0.09 \mathrm{~m}$ level for 11 sections of the main channel and 4 sections of intake channel respectively for $\mathrm{Q}_{\mathrm{r}}=0.21$ is shown. Comparison of the results shows the appropriate accuracy of RSM turbulence model in prediction of the flow field both along the main and intake channels.

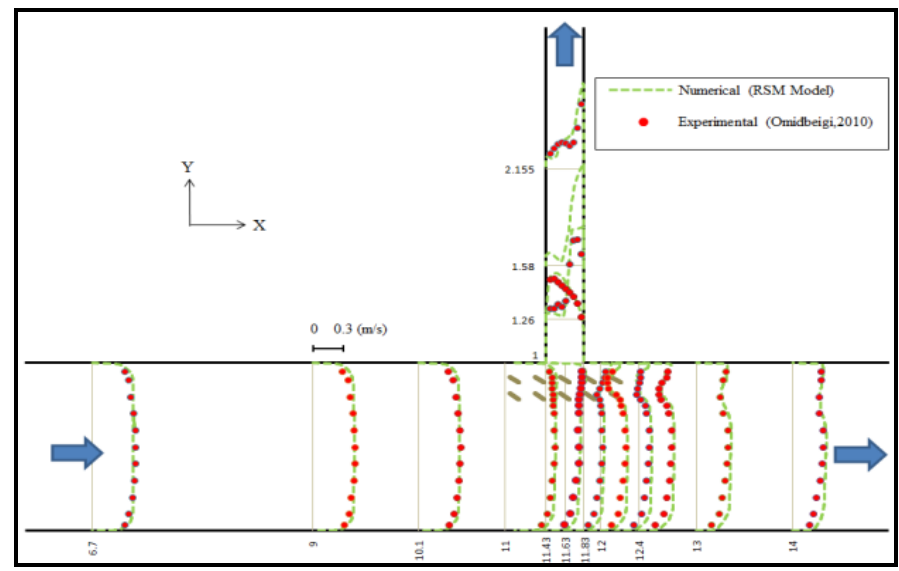

Figure 5. numerical and experimental transverse velocity profiles in $\mathrm{Z}=0.09 \mathrm{~m}\left(\mathrm{Q}_{\mathrm{r}}=0.21\right)$ 


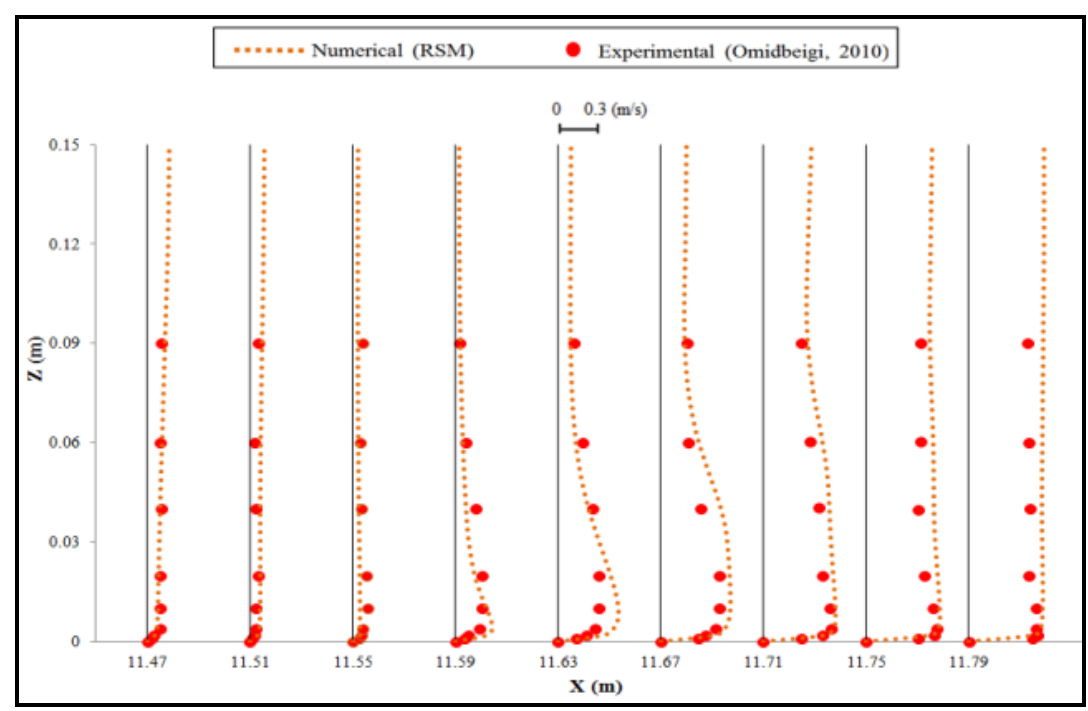

Figure 6. numerical and experimental depth velocity profiles in $y=1.58 \mathrm{~m}\left(\mathrm{Q}_{\mathrm{r}}=0.21\right)$

In Figure 6 the depth profile of velocity for $\mathrm{Q}_{\mathrm{r}}=0.21$ the intake channel has been represented. The under study section is in section of $y=1.58 \mathrm{~m}$ in the intake channel, where the flow turbulence is high. Considering the Figure 8 , it can be said that in the intake channel, the results from the RSM turbulence model has good consistency with the experimental results. The average percentage of relative error is $7 \%$ approximately.

\section{Results and Discussion}

\subsection{Investigation of Vanes Dimensions and Intake Ratio}

In this section the effect of vanes dimensions on formation location of the saddle point is investigated. The vanes configuration is based on what has been considered in most of the pervious studies [5]. The vanes configuration parameters are shown in Table 3.

Table 3. Vanes configuration parameters

\begin{tabular}{|c|c|c|c|}
\hline$\delta_{\mathrm{s}}$ & $\delta_{\mathrm{n}}$ & $\delta_{\mathrm{b}}$ & $\alpha$ \\
\hline $3 \mathrm{H}_{\mathrm{v}}$ & $8 \mathrm{H}_{\mathrm{v}}$ & $3 \mathrm{H}_{\mathrm{v}}$ & $20^{\circ}$ \\
\hline
\end{tabular}

Figure 7 shows the channel's near bed streamlines $(z=0.004 m)$ for three rates of intake of $0.11,0.16$ and 0.21 when $\mathrm{H}_{\mathrm{v}} / \mathrm{d}=0.2$ and $\mathrm{L}_{\mathrm{v}} / \mathrm{H}_{\mathrm{v}}=3$. It can be observed that by the increase in the intake ratio the saddle point is formed at a distance closer to the intake entrance, and when the intake ratio increases to 0.21 of the total flow, the saddle point forms at outside of the intake channel and the return flows are entered into the intake from the right hand corner of the intake entrance. Therefore, increasing the intake ratio has a negative effect on intake conditions.
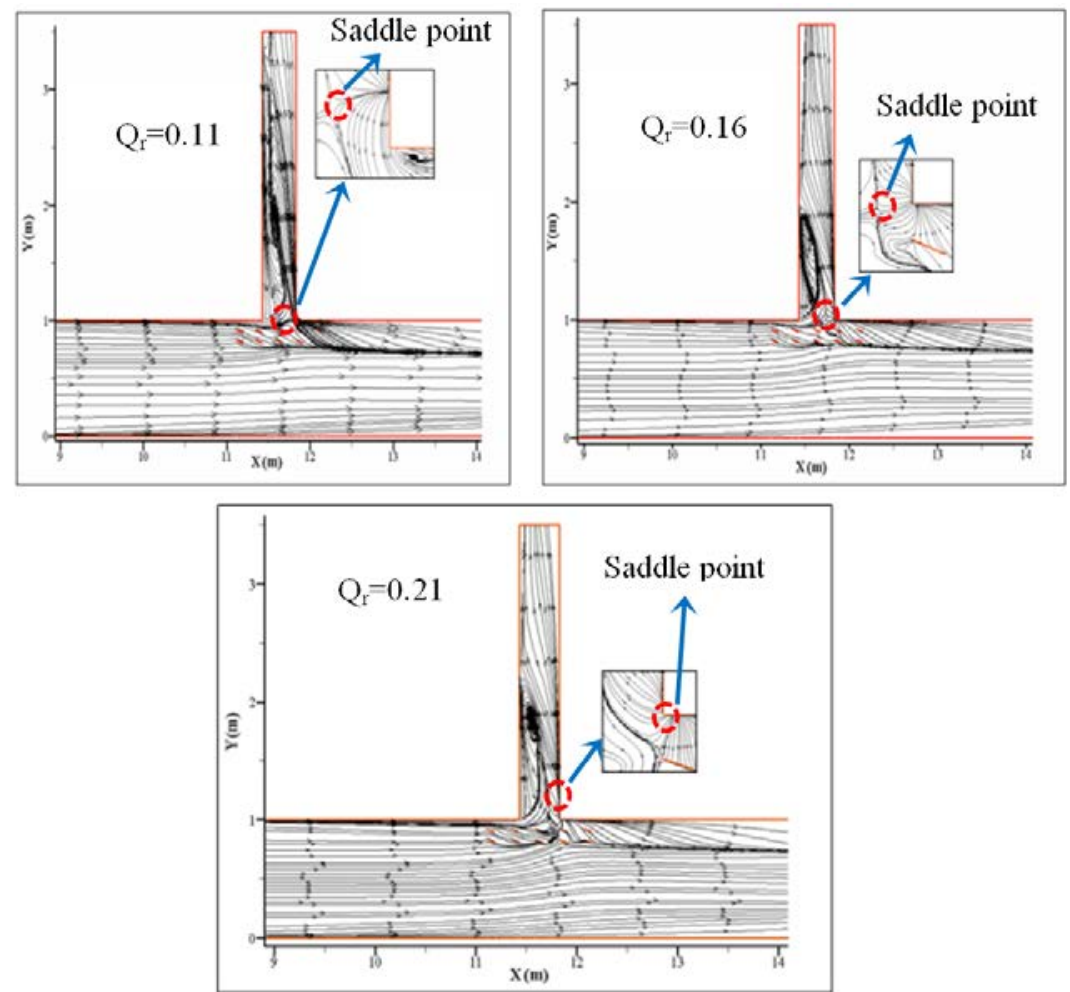


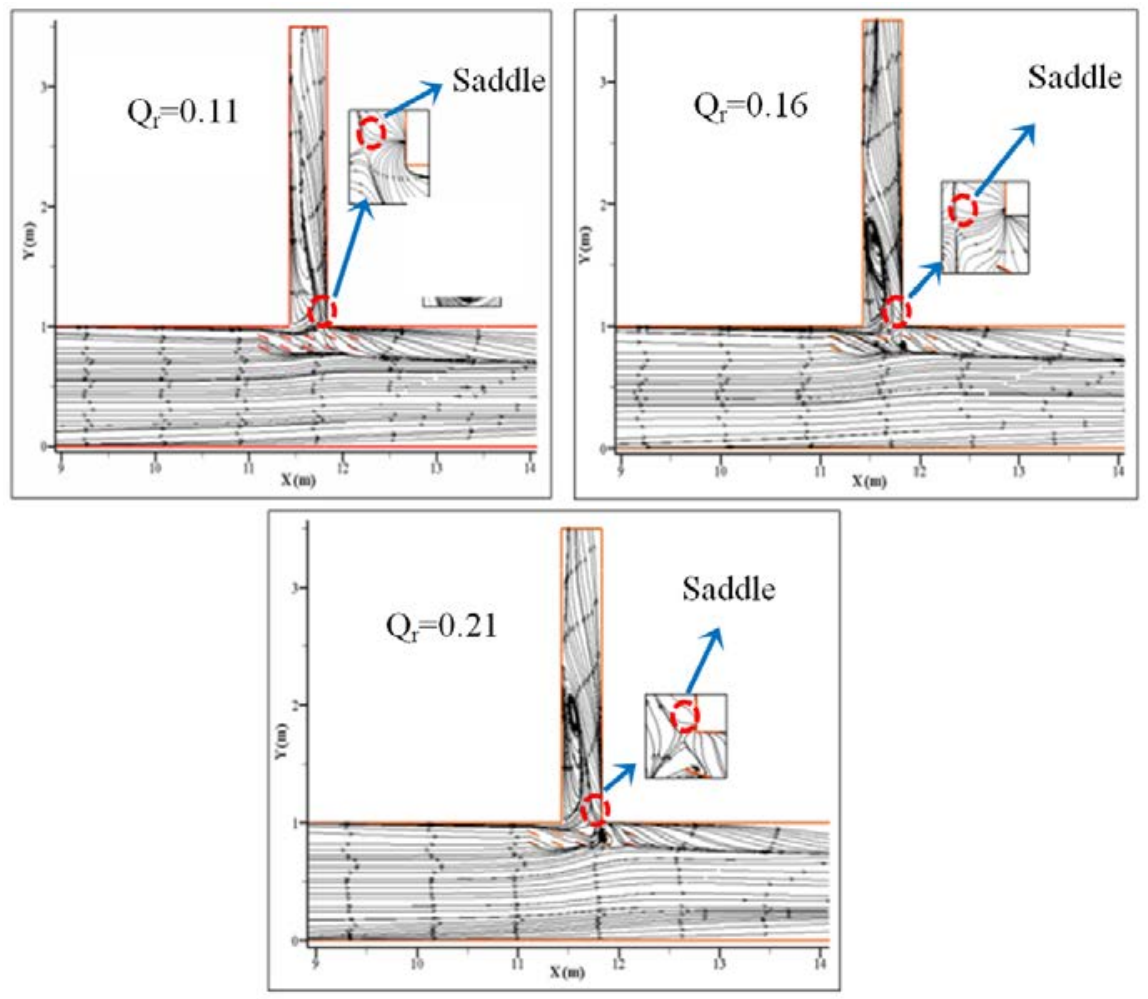

Figure 8. Formation location of the saddle point in different intake ratios when $\mathrm{H}_{\mathrm{v}} / \mathrm{d}=0.2$ and $\mathrm{L}_{\mathrm{v}} / \mathrm{H}_{\mathrm{v}}=4$
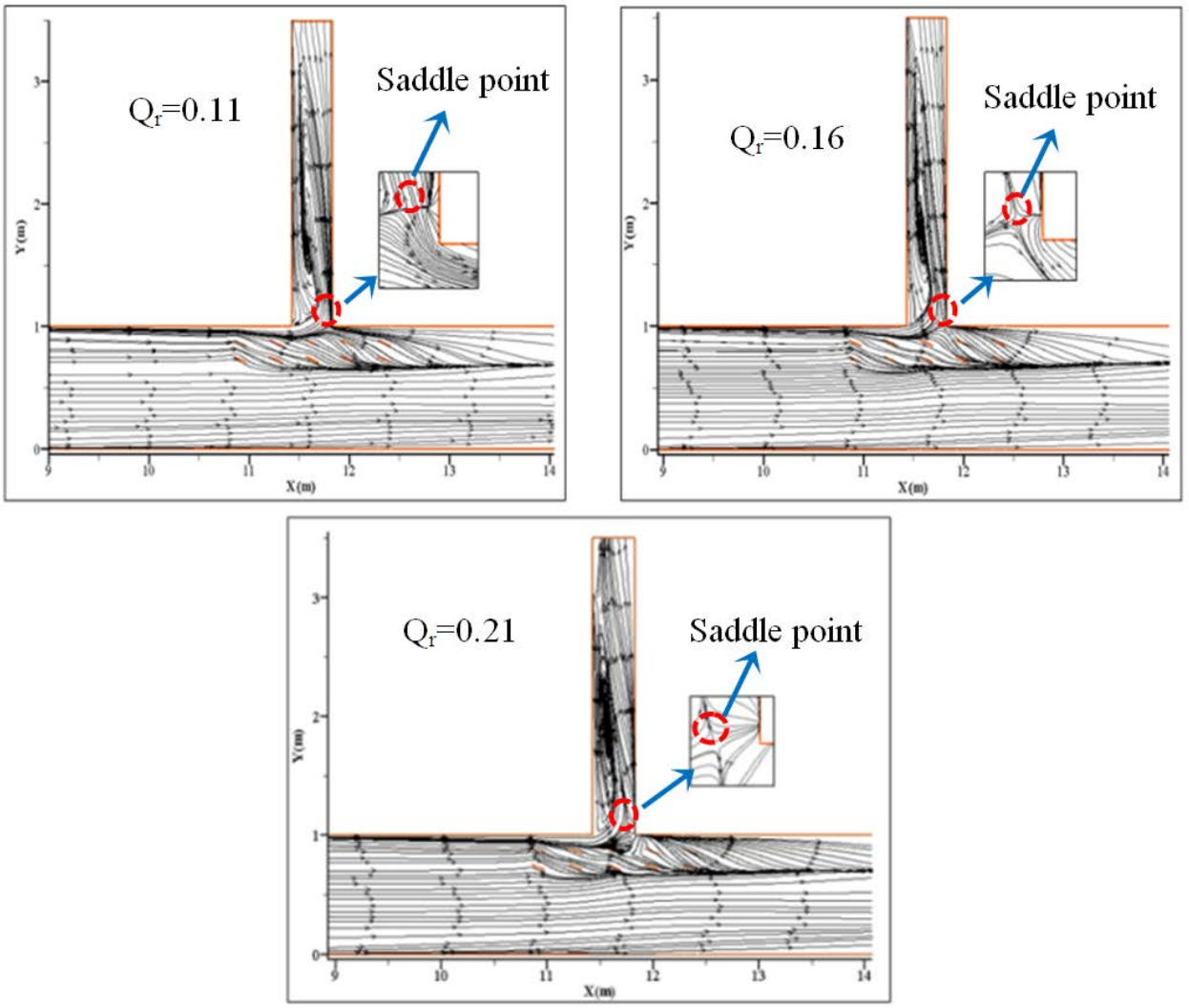

Figure 9. Formation location of the saddle point in different intake ratios when $H_{v} / d=0.3$ and $L_{v} / H_{v}=3$

Figure 8 represents the channel's near bed streamlines for $\mathrm{H}_{\mathrm{v}} / \mathrm{d}=0.2$ and $\mathrm{L}_{\mathrm{v}} / \mathrm{H}_{\mathrm{v}}=4$ and three rates of intake of $0.11,0.16$ and 0.21 . Considering this Figure, it can be observed that by the increase in the intake ratio the saddle point is formed at a distance closer to the intake entrance. The reason for this phenomenon is that by the increase in the intake ratio, the intake suction is increased and gets strengthened.
The channel's near bed streamlines in presence of the vanes with $H_{v} / d=0.3$ and $L_{v} / H_{v}=3$ for three intake ratios of $0.11,0.16$ and 0.21 has been presented in the Figure 9 . Considering this figure, it can be observed that the more the rate of intake is increased the saddle point location gets more close to the intake channel entrance. For this height of the vanes, when $\mathrm{L}_{\mathrm{v}} / \mathrm{H}_{\mathrm{v}}=4$, in intake ratios of 0.11 and 0.16 the streamlines are similar to $\mathrm{L}_{\mathrm{v}} / \mathrm{H}_{\mathrm{v}}=3$. 
Comparison of Figures. 9 and 10 shows that when $\mathrm{H}_{\mathrm{v}} / \mathrm{d}=0.3$ increasing the vanes length has a negative effect on intake conditions, and causes formation of return flows toward the intake channel.

Figure 11 shows the channel's near bed streamlines for three rates of intake of $0.11,0.16$ and 0.21 in a condition when $\mathrm{H}_{\mathrm{v}} / \mathrm{d}=0.4$ and the ratio of $\mathrm{L}_{\mathrm{v}} / \mathrm{H}_{\mathrm{v}}$ is equal to 3 . Figure 7 shows that in rates of intake more than 0.11 of total flow, the saddle point is not formed at the intake entrance. Since this zone is formed by the participation of interaction between the secondary flow in the intake entrance, a downward flow that is formed from the collision of the flow to the downstream edge of the intake entrance as well as the counterclockwise flow existing in the main channel, so non-formation of the saddle point in the mentioned conditions can be attributed to these factors. When $\mathrm{L}_{\mathrm{v}} / \mathrm{H}_{\mathrm{v}}=4$ for this height of the vanes the formation location of saddle point is the same.

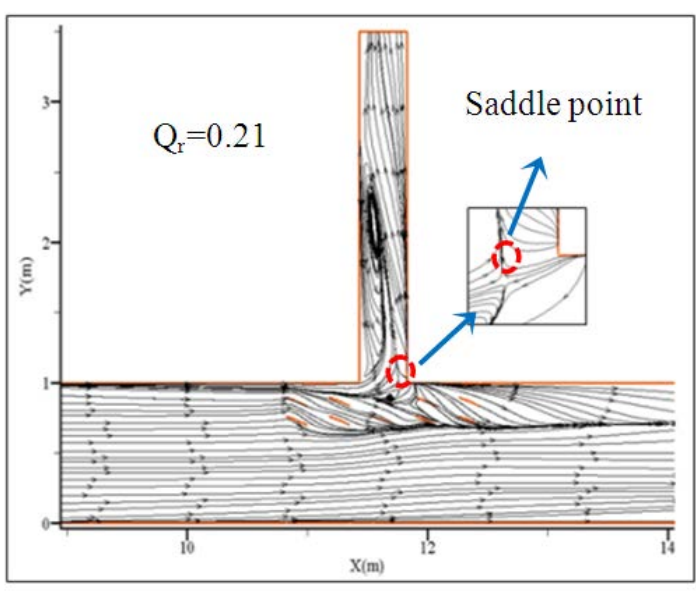

Figure 10. Formation location of the saddle point in different intake ratios when $\mathrm{H}_{\mathrm{v}} / \mathrm{d}=0.3$ and $\mathrm{L}_{\mathrm{v}} / \mathrm{H}_{\mathrm{v}}=4$

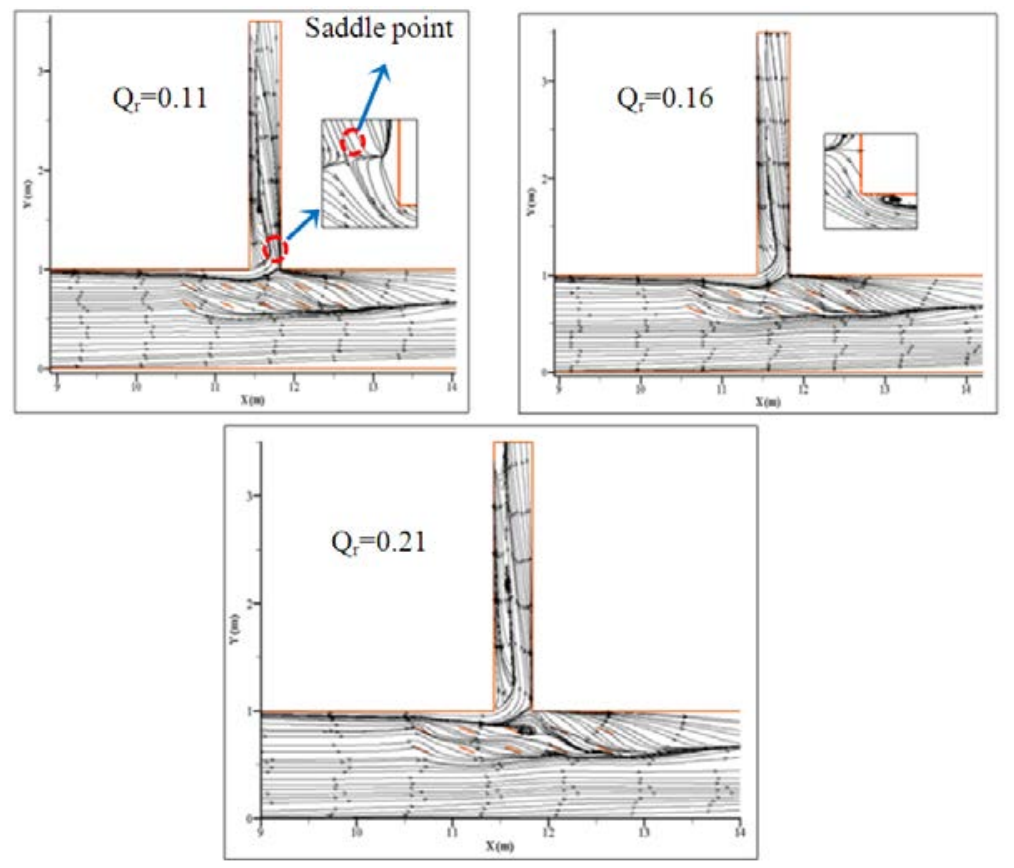

Figure 11. Formation location of the saddle point in different intake ratios when $H_{v} / d=0.4$ and $L_{v} / H_{v}=3$

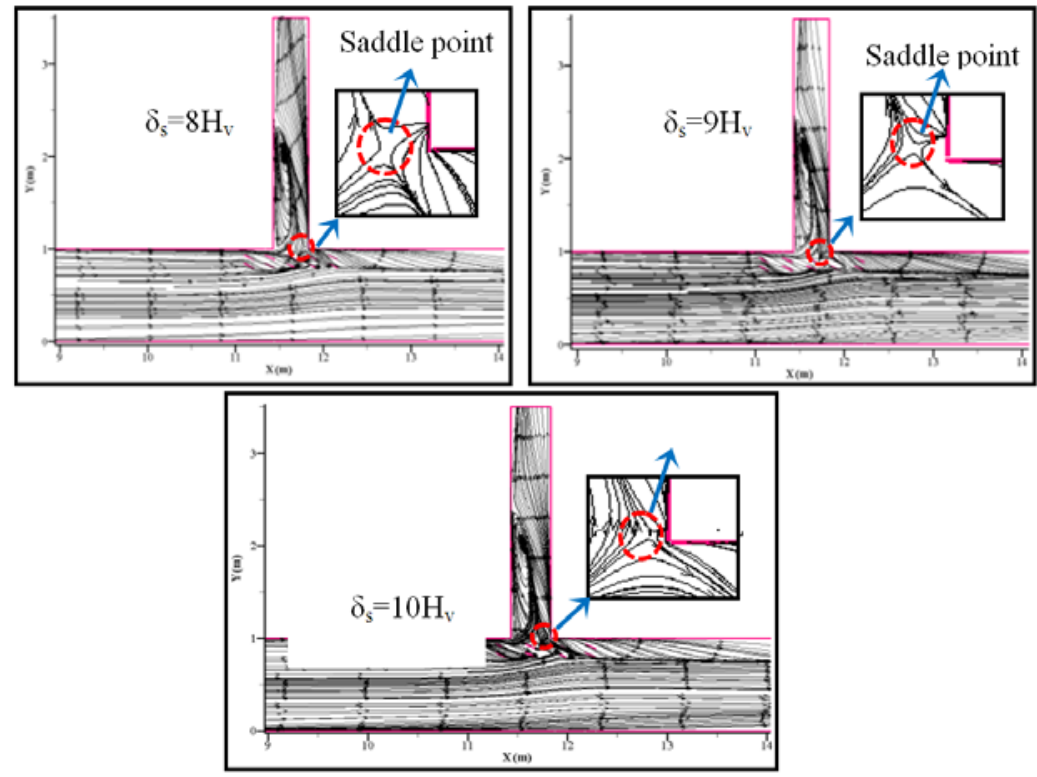

Figure 12. Changes of formation location of the saddle point with longitudinal inter-vanes distnace $\left(\delta_{\mathrm{n}}=3 \mathrm{H}_{\mathrm{v}}, \alpha=25\right.$ and $\left.\mathrm{Q}_{\mathrm{r}}=0.21\right)$ 

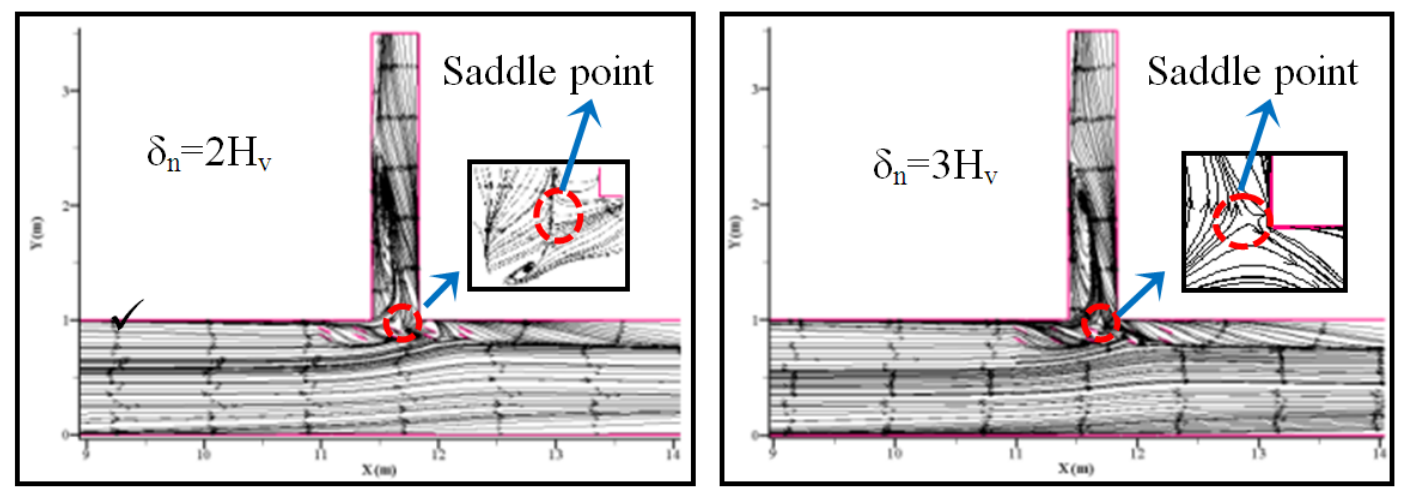

Figure 13. Changes of formation location of the saddle point with transverse inter-vanes distnace $\left(\delta_{\mathrm{s}}=10 \mathrm{H}_{\mathrm{v}}, \alpha=25\right.$ and $\left.\mathrm{Q}_{\mathrm{r}}=0.21\right)$
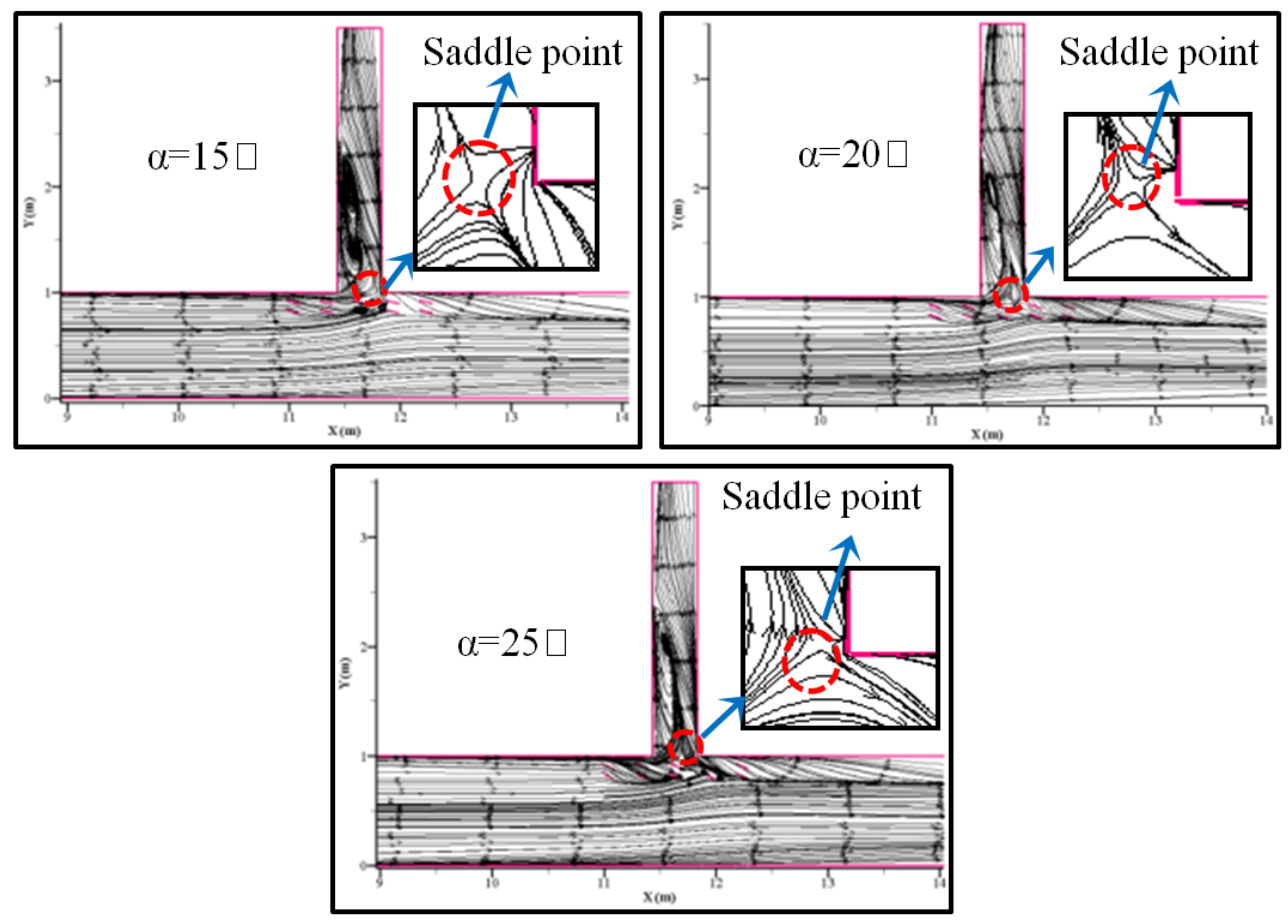

Figure 14. Changes of formation location of the saddle point with angle of the vanes $\left(\delta_{\mathrm{s}}=10 \mathrm{H}_{\mathrm{v}}, \delta_{\mathrm{n}}=3 \mathrm{H}_{\mathrm{v}}\right.$ and $\left.\mathrm{Q}_{\mathrm{r}}=0.21\right)$

\subsection{Investigation of Vanes Configuration}

Considering the variety of the figures, and similarity of the results obtained from the simulations for different configurations and discharge ratios, this section only represents the results of certain simulations.

Effect of vanes configuration on formation location of the saddle point is investigated in this section. $\mathrm{H}_{\mathrm{v}} / \mathrm{d}=0.2$ and $\mathrm{L}_{\mathrm{v}} / \mathrm{H}_{\mathrm{v}}=4$ that are the appropriate parameters for vanes dimensions has been considered for the simulations of this section [5].

Figure 12 shows the effect of longitudinal inter-vanes distance on formation location of the saddle point when $\delta_{\mathrm{n}}=3 \mathrm{H}_{\mathrm{v}}$ and $\mathrm{Q}_{\mathrm{r}}=0.21$. Changing the longitudinal distance between vanes does not have a remarkable effect on saddle point, and formation location of this point is independent from this parameter.

Changes of formation location of the saddle point with transverse inter-vanes distnace when $\delta_{\mathrm{s}}=10 \mathrm{H}_{\mathrm{v}}$ and $\mathrm{Q}_{\mathrm{r}}=0.21$. is shown in Figure 13. As can be seen in this figure, increasing the inter-vane transverse distance has a positive effect on intake conditions and results in formation of saddle point in a distance closer to the intake entrance and no flow returns into the intake channel.

As can be seen in Figure 14, formation location of the saddle point is independent from angle of submerged vanes with respect to the flow direction.

\section{Conclusion}

In this research effects of submerged-vanes dimensions and configuration and intake ratio on formation location of the saddle point was investigated. The results of the study showed that although vanes length is not effective in formation location of the saddle point, increasing the vanes height results in formation of the saddle point in a distance farther from the intake entrance and omission of return flows. Also, utilization of submerged vanes with larger transverse distance has a positive effect on intake conditions, because no flow from downstream side of the intake channel returns to it. But formation location of the saddle point is independent from longitudinal inter-vanes distance and angle of submerged vanes with respect to the flow direction. Finally, by increasing the intake ratio, the saddle point forms at a distance closer to the intake 
entrance, and the return flows are entered into the intake from the downstream corner of the intake entrance.

\section{References}

[1] Barkdoll, B. D., "Sediment control at lateral diversions," $P h D$ dissertation, Civil and Environmental Engineering, University of Iowa, Iowa city, Iowa. 1997.

[2] “FLUENT user's guide manual-version 6.3.26," Fluent Incorporated, New Hampshire., 2006.
[3] Neary, V. S., Sotiropoulos, F., and Odgaard, A. J., "Threedimensional numerical model of lateral-intake inflows," Journal of Hydraulic Engineering, ASCE, 125 (2):126-140. 1999.

[4] Omidbeigi, M., A., "Experimental investigation and three dimensional numerical simulation of lateral intake with submerged vanes," M.Sc. dissertation. Tarbiat Modares University, Tehran, Iran. 2010.

[5] Seyed Mirzaei, S., H., "Determination of appropriate dimensions and configuration of submerged vanes in lateral intake of river using FLUENT mathematical model,” M.Sc. dissertation. Tarbiat Modares University, Tehran, Iran. 2011.

[6] Taylor, E., "Flow characteristics at rectangular open channel junction," Journal of Hydraulic Engineering, ASCE, 10 (6).893902. Jun. 1944. 